Harvard Data Science Review • Issue 3.3, Summer 2021

\title{
Remembering Robert Lue: Giving Students "Not a Data Science Course, but a Data Science Life"
}

\section{Xiao-Li Meng ${ }^{1,2}$}

${ }^{1}$ Department of Statistics, Faculty of Arts and Sciences, Harvard University, Cambridge, Massachusetts, United States of America,

${ }^{2}$ Harvard Data Science Review, Harvard Data Science Initiative, Harvard University, Cambridge, Massachusetts, United States of America

Published on: Jul 30, 2021

DOI: https://doi.org/10.1162/99608f92.5461cafb

License: Creative Commons Attribution 4.0 International License (CC-BY 4.0) 
Editor-in-Chief's Note: Robert Lue, HDSR founding co-editor for Data Science Education, passed away on November 11, 2020, at age 56, after a brief battle with an aggressive cancer. Rob was a force of nature, in the fullest sense of the phrase. He served in more educational leadership roles at Harvard and beyond than anyone I know, and he brought to each role a spirit of innovation and devotion. As a world-renowned science educator, Rob viewed data science, in its infinite versatility, as an unprecedented arena in which to forge entryways for students of all backgrounds to engage in critical thinking and reasoning in subjects that spark passion and, more broadly, to re-imagine liberal arts and science education as a whole. This vision will take generations to realize, but Rob has left with us a host of ideas and initiatives upon which to build, with the foremost amongst them being LabXchange, a fast-growing online community for learning, sharing, and collaboration.

My first encounter with Rob was during 2004-2005, when I became the chair of the statistics department. I got an email from an assistant to Dean Lue that the Dean wanted to see me. I naturally got a bit nervous. Why did a dean want to see me? Had I done something wrong or incompetent as a new chair? My only comfort lay in the fact that, as indicated by his assistant, the Dean would come to my office. I figured that things could not be too bad, as otherwise Dean Lue would presumably have summoned me to his office.

The meeting turned out to be the beginning of a 15-year friendship and partnership. I am profoundly saddened that I am left alone to reminisce about it. On the day we met, Rob, as the Dean of the Summer School, was in the midst of a long process of reaching out to each chair to discuss courses that each department could offer. Most deans do not visit each department chair's office, but Rob was not most deans. Yet I doubt that he would have considered the visit to be special in any way. A high level of courtesy, engagement, and attention to the needs of others was second nature to Rob, who truly was a people person. He could make any new acquaintance feel like an old friend after one conversation. He did so by being an effortlessly engaging interlocutor and an attentive listener. One was drawn to him because of his infectious passion and energy, and his ever-bubbling fountain of ideas.

When I became a dean myself eight years later, I needed a partner to go on trips to engage alumni and the general community. With all his great traits, and because of the rich experiences he could share, Rob became the perfect fellow ambassador. During my five-year deanship, Rob and I did 'road shows' in multiple countries. He spoke passionately about undergraduate education from the perspective of his role as the Director of Life Science Education. As the founding Faculty Director of HarvardX, he excited audiences about online learning. Finally, as the Richard L. Menschel Faculty Director of the Derek Bok Center for Teaching and Learning, he conversed with alumni about pedagogical training and innovations for faculty and teaching fellows. (For my part, I talked about professional development for graduate students, and graduate education in general, from the perspective of my role as the Dean of Graduate School of Arts and Sciences.) 
For most faculty members, having any one of the roles just mentioned is sufficient to keep them busy. But these three roles were only facets of Rob's truly large-than-life persona as a science educator and community builder. For example, he served as the founding Faculty Director of the Harvard Ed Portal, a community engagement center on Harvard's Allston campus, from 2008 until his tragic passing in late 2020. Earlier that year, he launched the Lemann Program on Creativity and Entrepreneurship, in which context he took on yet another leadership role that required an innovative mind and superb engagement skills. Rob was virtually unstoppable; there was no administrative responsibility that he would not assume. As a matter of fact, one time our Faculty of Arts and Sciences conducted a study on administrative burdens on the faculty, which provided a histogram of the number of committees on which faculty members served. On the extreme right tail, there was a bin for serving on more than 12 committees. There was only one faculty member who fell into that bin. We all knew that was Rob, despite the purported anonymity of the study (incidentally, this is a clear example of how individuals can be identified from aggregated data). What made Rob stand out, however, was not the quantity of his roles but rather the quality of what he did, and the unbounded vision and energy that he brought to every enterprise fortunate enough to have his leadership.

Upon his completion of his tenure as the founding faculty director of $\underline{\text { HarvardX }}$, I was fortunate enough to have Rob join HDSR as its founding Co-Editor for Data Science Education. Rob played a critical role in the formation of HDSR, and indeed our logo was created through his working with a design team. His vision for data science education was most clearly laid out in his article in HDSR, "Data Science as a Foundation for Inclusive Learning” (Lue, 2019), as well as in his interview with the co-chairs of the US National Academies' report on undergraduate education in data science (Hass, Hero, \& Lue, 2019), where he proposed the idea of using "data science as an overarching theme to organize liberal arts education in the digital age.”

Among many calls for inclusive learning, Rob’s stood out because it fully embraced the essence of being inclusive. To Rob, inclusive learning is not about ' I include you, and you learn from me or about whatever interests me.' Rather, it is about creating environments and content to enable learning and to maximize its efficiency and depth for students (and others) in subjects that they are most passionate about. This aspiration is clearly highlighted in Rob’s abstract (Lue, 2019):

The widening application of data science methods to nearly every field imaginable in the natural sciences, social sciences, and humanities opens up avenues for engagement based on what students care about and the challenges they are most interested in tackling. Data science therefore provides an opportunity to build an inclusive STEM curriculum from the ground up that connects with multiple disciplines as well as the personal passions of students.

Rob put this "ground up" idea into action in launching LabXchange, a collaborative ecosystem grounded in a powerful online education platform. LabXchange enables and empowers curious minds to explore paths in science, and aims to create equitable opportunities for success and prosperity through tailored learning for unique needs, interests, and goals. Its innovative pathway feature gives learners a versatile new way to engage 
with learning content, and complements educators' capabilities, helping them to deliver better learning outcomes. As a powerful collective of educational organizations, LabXchange inspires future change-makers and provides them with the skills they need to meet the world's biggest challenges—critical thinking, experimental design, data science, and more.

Rob's passing is a profound loss to the world of education. As much as I tried to be an effective communicator and teacher myself, his ability to articulate and to generate enthusiasm was simply beyond my reach. For those readers who did not have the opportunity to listen to him, you are especially invited to watch his remarks at the opening session of the inaugural HDSR symposium last year (roughly 10 minutes starting from 18:00), to appreciate his infectious enthusiasm and hear directly from him about his vision of using data science education as a foundation for re-imagining the entire project of liberal arts and science education.

Personally, I doubt that I could ever have a more inspiring education partner and friend. There was no idea of mine that would be too crazy for him, and vice versa. It was our shared 'craziness' that brought us together to undertake adventures on multiple projects, from me joining him to teach summer programs for life science students to his joining me to launch Harvard Data Science Review, despite the fact that I have no training in life science, and Rob did not have any degree in data science. But to Rob, what mattered was not much one's degree, but rather one's 'ability to bootstrap into what one cares about,' as he told the audience during his aforementioned opening remarks, "And I bet that not a lot of you have a degree in data science. You come to it from some other field, and you bootstrapped it to what it is now. So you are shaping it. And that's what our students need to do. We don’t shape them. They will shape the field with us.”

Rob, I miss you dearly. There is no more fitting way to conclude this memorial than by quoting your passionate concluding call at the HDSR's opening symposium:

Keep in mind that what we are trying to do is hopefully give our students not a data science course, but a data science life. And it is their lives and their stories.

\section{Acknowledgments}

I thank Suzanne Smith and Gaurav Vazirani for their great comments and help in putting together this memorial, and many HDSR board members for their sympathy and moral support during the most difficult time of coping with Rob's sudden passing, for both HDSR and for me personally. The appendix shares some responses from the board members reacting to the announcement of Rob's passing I made to the board (which forms the base for this memorial), as they provided a glimpse into Rob’s life as a person and as an educator, and how much he was loved and respected by many.

\section{Disclosure Statement}

Xiao-Li Meng has no financial or non-financial disclosures to share for this editorial. 


\section{References}

Haas, L., Hero, A., \& Lue, R. A. (2019). Highlights of the National Academies report on "Undergraduate Data Science: Opportunities and Options.” Harvard Data Science Review, 1(1).

https://doi.org/10.1162/99608f92.38f16b68

Lue, R. A. (2019). Data science as a foundation for inclusive learning. Harvard Data Science Review, 1(2). https://doi.org/10.1162/99608f92.c9267215

\section{Appendix: Reactions from HDSR Board Members}

This is a profound loss for all of us who knew him. He brought sunshine to all in his many activities. You captured his broad and enduring impact on all of us in your letter. Thank you for writing it.

This is terrible news. I interacted with Rob and am shocked that he passed away so young, so vibrant, so generous, and with such a great sense of humor.

I was so intensely saddened to hear about Rob. I wanted to thank you for sharing this remembrance of him, which added even more to the warm picture I had about his impacts throughout the Harvard community and beyond and the very high esteem I had for Rob.

This is the single most devastating piece of news. I'm at a loss for words. Rob will be dearly missed.

What very sad news. I remember his creativity, enthusiasm, and 'can-do' approach during early days of EdX and portal activities, his inclusive approach to conversations and his openness to conversations about everything. Your reflections are really true to the person.

I am so very sorry. I met Rob when he and you kindly invited me to Harvard in the early days of XXX. His insight and collegiality were instantly apparent, and I regret that we didn't have a chance to collaborate.

Rob's passing is a great loss to the teaching profession. My condolences to you, all his colleagues, and his family. 
This is incredibly sad news - it is hard to imagine Harvard and our HDSI community without Rob. He was always a force of energy, excitement, and initiative and will be sorely missed.

Always with incredible humility, we must appreciate how precious and evanescent life really is. It seems only yesterday we were all at Troquet together celebrating and enjoying wonderful company with Rob and our other board members. Hoping you are staying safe and well; we will continue to carry forth Rob's memory in our good work.

(C)2021 Xiao-Li Meng. This editorial is licensed under a Creative Commons Attribution (CC BY 4.0)

International license, except where otherwise indicated with respect to particular material included in the article. 